Published in final edited form as:

Am J Med Genet A. 2012 December ; 158A(12): 3056-3060. doi:10.1002/ajmg.a.35550.

\title{
Increased Risk of Breast Cancer in Women with NF1
}

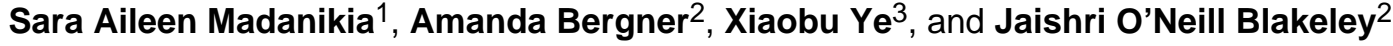 \\ 1 Johns Hopkins School of Medicine, Johns Hopkins University, Baltimore MD \\ 2Johns Hopkins Comprehensive Neurofibromatosis Center, Johns Hopkins University, Baltimore, \\ MD \\ 3Johns Hopkins Department of Neurological Surgery, Johns Hopkins University, Baltimore, MD
}

\begin{abstract}
Neurofibromatosis type 1 (NF1) is a common autosomal dominant disorder associated with increased risk for neoplasms. Two studies in the United Kingdom have indicated that women with NF1 (particularly women under 50) may also be at increased risk of breast cancer. No such study has been done to date in the United States. Chart review for breast cancer diagnoses was undertaken for 126 women with NF1 followed at Johns Hopkins who were 20 years of age or older. Four of 126 women who met eligibility criteria were diagnosed with breast cancer $(3.2 \%$ over 15 years). The unadjusted standardized incidence ratio (SIR) for breast cancer in the NF1 population between the ages of 20 and 49 was 2.68 ( $\mathrm{P}=0.076$, 95\% CI: 0.68-7.29) based on incidence rates of breast cancer in the general population taken from the Surveillance Epidemiology and End Results (SEER) database. The unadjusted SIR for women with NF1 250 was $0.81(\mathrm{P}=0.84,95 \% \mathrm{CI}: 0.041-4.01)$. When adjusted for race, the rate of NF1 in the general population and time of diagnosis, the SIR was 4.41 ( $\mathrm{P}=0.0049,95 \%$ CI: 1.12-12.00) for women $<50$ versus $0.94(\mathrm{P}=0.95,95 \% \mathrm{CI}$ : $0.047-4.65)$ for women $\geq 50$. The trend of a higher-thanexpected number of breast cancer cases in women $<50$ with NF1 agrees with the prior studies from the literature. Cumulatively, the data suggests an increased risk of breast cancer for women with NF1 <50 years old, implying a need for closer surveillance and the establishment of screening guidelines for this patient population.
\end{abstract}

\section{Keywords}

neurofibromatosis 1; breast neoplasms; historical cohort study; SEER program

\section{INTRODUCTION}

Neurofibromatosis type 1 (NF1) is an autosomal dominant disorder, which has an approximate incidence of 1 in 2500 and a prevalence of 1 in 4000 [Evans et al., 2010]. Patients with NF1 are at risk for myriad systemic manifestations resulting from the lack of neurofibromin including: dermatologic markings, vascular disease, bone deformities and cognitive difficulties [Montani et al., 2011; Brunetti-Pierri et al., 2008; Ardern-Holmes and North, 2011]. Importantly, $N F 1$ is a tumor suppressor gene, and a major concern for the clinical care of patients with NF1 is the increased risk for neoplasms.

Corresponding Author: Jaishri Blakely Postal address: 600 N. Wolfe St., Phipps 117, Baltimore MD 21287 jblakel3@ jhmi.edu Telephone: +1 (410) 502-6732 Fax: +1 (410) 614-0845.

Conflict of Interest Disclosure: All authors report no relevant financial disclosures. 
The NF1 gene product, neurofibromin, stimulates the intrinsic hydrolysis of Ras-GTP to Ras-GDP to diminish signaling through the Ras-MAPK pathway. In the absence of neurofibromin (double inactivation by somatic NF1 mutation), the active (GTP-bound) form of Ras drives cell proliferation [Riccardi, 2010], an important step in tumorigenesis. Benign dermal neurofibromas are the most common tumor in NF1. Plexiform neurofibromas, complex peripheral nerve sheath tumors, develop in roughly $30 \%$ of patients with NF1. These often result in neurologic morbidity and on some occasions transform into aggressive sarcomas called malignant peripheral nerve sheath tumors (MPNSTs) [Evans et al., 2002; Huson et al., 1988]. NF1 patients are also at risk for developing low- and high-grade gliomas and systemic malignancies including gastrointestinal stromal tumors (GISTs), somatostatinomas, pheochromocytomas, leukemias, and breast cancer [Walker et al., 2006; Brems et al., 2009; Evans et al., 2011].

Breast cancer has also been shown to be associated with NF1. A retrospective study from Manchester, England, identified a cohort of 304 female patients with NF1 age 20 and older [Sharif et al., 2007]. Compared with breast cancer rates from the general population, women with NF1 had a 5-fold increased risk of being diagnosed with breast cancer, with the most common type of breast cancer being infiltrating ductal carcinoma. The increased risk appeared to be specific to women under 50 years of age [Sharif et al., 2007]. A prospective study of cancer incidence in individuals with NF1 found that the overall risk of developing any cancers (excluding non-melanoma skin cancers and benign tumors) was increased 6.5 fold in NF1 patients younger than 50 (standardized incidence ratio [SIR] $=6.5, \mathrm{P}<0.0001$, 95\% confidence interval [CI]: 4.1-9.8) [Walker et al., 2006]. Specifically, they found that the risk of developing breast cancer was significantly higher in this age group (SIR $=4.0, \mathrm{P}$ $=0.037,95 \%$ CI: 1.1-10.3). Another study that looked at mortality in NF1 found that women with NF1 were 3.5 times more likely to die from breast cancer than women in the general population (PMR=3.5; 95\% CI, 1.3-7.7) [Evans et al., 2011]. Finally, there have been numerous case reports in the literature of patients with NF1 who presented with ductaltype breast carcinomas, including a male patient who was diagnosed with bilateral ductal carcinoma at age 18 [Wilson et al., 2004]. To date, there have been no formal investigations of the relationship between breast cancer and NF1 in the United States. The objective of this study was to assess if the association between women with NF1 and a higher risk of breast cancer reported in the epidemiology study in the United Kingdom (UK) was also true among the adult women seen in the Johns Hopkins Comprehensive Neurofibromatosis Center (JHCNC).

\section{METHODS Data collection}

Collection of data was undertaken with approval from the Johns Hopkins Institutional Review Boards. Patients seen between 2003-2010 at Johns Hopkins University were identified through the JHCNC, a referral center that sees patients with NF1, NF2 and schwannomatosis from across the United States. This study included women with a definitive diagnosis of NF1 based on NIH criteria who were at least 20 years of age at the time of record review [National Institutes of Health Consensus Development Conference, 1988]. Patient records were obtained from the Johns Hopkins Hospital (JHH) Electronic Patient Record (EPR), JHH paper medical record charts, and the JHH Oncology Clinical Information Systems (OCIS) database. Charts were primarily examined for breast cancer diagnoses. The date of diagnosis was noted along with the date upon which the patient established care at the JHCNC. Benign conditions such as uterine fibroids, breast cysts, fibrocystic changes, and microcalcifications were not recorded. Tissue diagnoses were noted whenever available. 
To explore the effect of referral bias within a tertiary referral center, a comparator group for this study was established from the Johns Hopkins Comprehensive Marfan Center. This group was selected for comparison because Marfan syndrome is inherited in a similar fashion as NF1, has similar penetrance, is a medically complex syndrome and has an established specialty center at the same institution but is not known to be associated with any neoplasms [Shirley and Sponseller, 2009; Jondeau et al., 2011]. A similar search was undertaken in this population to identify women with definitive Marfan syndrome aged 20 and older.

\section{Comparison to population data}

To calculate a standardized incidence ratio for breast cancer in the female NF1 population, incidence rates of breast cancer in the general population from the Surveillance Epidemiology and End Results (SEER) database were used for the years 1975-2007 [SEER, 2012]. Women were factored into the calculation in the year that they reached their $20^{\text {th }}$ birthday. The age group- and calendar-period specific person-years at risk were multiplied by the incidence rate for that particular calendar year to produce the expected number of cases. Individuals were censored after diagnosis of breast cancer or death. The SIR was calculated based on the number of observed cases compared to the number of expected cases (step 1). P-values for SIR were calculated using a chi-square test. Confidence intervals were calculated using the mid-P exact test using OpenEpi. All statistical tests were 2-sided and $\mathrm{P}$ values less than 0.05 were considered significant.

\section{Adjustment for Race and Prevalence of NF1}

To adjust for race, incidence rates of breast cancer for white and black women were adjusted to the proportion of each in the NF1 population at the JHCNC (step 2). SEER incidence rates for breast cancer in black and white women are available online from seer.cancer.gov. For the NF1 population at Johns Hopkins, $72 \%$ are white (including Asian, Hispanic and unspecified) and $28 \%$ are black. Rates were only available for black and white women from SEER, so Asian, Hispanic women and women with unspecified race were included as part of the white demographic for purposes of this calculation. The calculation for each calendarspecific year for both invasive and in situ cases of breast cancer was as follows: $(0.28 *$ incidence for black women $)+(0.72 *$ incidence for white women $)$.

Using the data from step 2, adjustments to SEER incidence data were made to account for cases of women with NF1 and breast cancer, women with NF1 in the general population, and the demographic characteristics of the population at the JHCNC (step 3). To account for cases of women with NF1 in the general population, the prevalence rate of 1 in 4000 was used [Evans et al., 2010]. For a population of 100,000 (the standard denominator used when reporting SEER cancer incidence data), this would equal 25 women with NF1 among 100,000 . To account for breast cancer cases among women with NF1, the previously reported value of an incidence of 14/304 was used to calculate an expected 1.15 cases of breast cancer in women with NF1 per year [Sharif et al., 2007]. To obtain an incidence ratio of breast cancer cases in the general population/total number of general population without NF1, 1.15 was subtracted from the numerator and 25 was subtracted from the denominator for each calendar year to obtain a calendar-year-specific incidence rate of breast cancer cases among women without NF1.

\section{Adjustment for time period of incidence}

An alternative way to examine the data is to assess the number of expected versus actual reported cases in the time period that begins with the date of the first breast cancer diagnosis for the cohort of women with NF1 at the JHCNC. Instead of using 1975 as a starting point (as previously done in steps 1-3), the year 1995 (the date of first known case from the 
JHCNC) was used (step 4). Other epidemiologic studies have used a similar method with SEER data in order to reflect time period sensitive factors such as diagnostic practices and treatments [Silverstein et al., 2003]. The same methodology as previously outlined for steps 1-3 above was used to calculate age- and calendar-year-specific incidence rates from 1995-2010.

\section{RESULTS}

At the time of this study, there were 506 total patients with NF1 enrolled in the JHCNC database. Of these patients, 126 were women $\geq 20$ years of age. A similar search of records from the Johns Hopkins Marfan Center yielded 47 women with a confirmed diagnosis of Marfan syndrome who were $\geq 20$ years of age (Table I). The NF1 cohort had a higher representation of black women ( $28 \%$ for NF1, $9 \%$ for Marfan syndrome); otherwise there were no statistically significant differences between groups with regard to demographic features.

The overall incidence of breast cancer in women with NF1 in the JHCNC from 1995-2010 was $3.2 \%$. There was a trend for a nearly 3 -fold increase in the risk of breast cancer in women with NF1 who are $<50$ years old compared to age-matched unadjusted incidence rates ( $\mathrm{SIR}=2.68 ; \mathrm{P}=0.076,95 \%$ CI: 0.68 to 7.29 ) (Table II). No such relationship was seen for women with NF1 250 years old ( $\mathrm{SIR}=0.81, \mathrm{P}=0.84,95 \%$ CI: 0.041 to 4.01 ). Across all ages, the unadjusted SIR was $1.71(\mathrm{P}=0.28,95 \% \mathrm{CI}$ : 0.54 to 4.12$)$. Among women with Marfan syndrome, the SIR was 0 across all age groups, as there were no observed cases of breast cancer in the 47 women studied in this cohort. Given the small number of patients in the Marfan syndrome cohort, the expected rate of diagnosis of breast cancer based on SEER data is 0.51 cases.

Adjustments for race and NF1 cases in the general population yielded essentially the same results (Table II). When race was adjusted for, the SIR of women $\angle 50$ was $2.68(\mathrm{P}=0.076$, $95 \%$ CI: 0.68 to 7.29 ). For women $\geq 50$ years old, the SIR was 0.81 ( $\mathrm{P}=0.84,95 \%$ CI: 0.041 to 4.01$)$. Across all ages the SIR was 1.70 ( $P=0.28,95 \%$ CI: 0.54 to 4.11$)$. When NF1 cases in the general population were subtracted out, the SIR for women $<50$ was $2.75(\mathrm{P}=0.067$, 95\% CI: 0.70 to 7.49 ). For women 250 years old the SIR was 0.82 ( $\mathrm{P}=0.84,95 \%$ CI: 0.041 to 4.04$)$. Across all age groups, the SIR was 1.72 ( $\mathrm{P}=0.27,95 \% \mathrm{CI}$ : 0.55 to 4.16 ).

Adjusting the data to match the time period of the diagnosis of breast cancer in NF1 patients yielded a slightly different picture (Table II). Pinpointing the dates of diagnosis and comparing them to the expected number of cases in the general population narrows the window of observation to a time period during which the cases actually occurred. For expected cases between 1995 and 2010 there was an SIR of 4.35 for women $<50(\mathrm{P}=$ $0.0054,95 \%$ CI: 1.11 to 11.83$)$. For women 250 years old the SIR was $0.94(\mathrm{P}=0.95,95 \%$ CI: 0.047 to 4.65 ). Across all ages the SIR was 2.29 ( $\mathrm{P}=0.089,95 \%$ CI: 0.73 to 5.51 ). When adjustments were made for race, NF1 cases in the general population, and time period of diagnosis, the results were essentially the same as the adjustment for time period of diagnosis only. The SIR for women $<50$ was 4.41 ( $\mathrm{P}=0.0049,95 \% \mathrm{CI}: 1.12$ to 12.00$), 0.94$ for women $\geq 50$ ( $\mathrm{P}=0.95,95 \%$ CI: 0.047 to 4.65$)$, and 2.30 for all ages $(\mathrm{P}=0.087,95 \% \mathrm{CI}$ : 0.73 to 5.55$)$.

Two women were diagnosed with breast cancer at Johns Hopkins Hospital after they had established care at the JHCNC (i.e., were known to have NF1 at the time of cancer diagnosis), while prior diagnoses of breast cancer for the other two were ascertained from clinical history during intake at the JHCNC. The tissue diagnosis for three of the four 
women was available. All showed a ductal origin with two being ductal carcinoma in situ and one being invasive ductal carcinoma (Table III).

\section{DISCUSSION}

The trend of a higher-than-expected number of breast cancer cases in women $<50$ years old with NF1 agrees with prior population-based studies from the UK [Walker et al., 2006; Sharif et al., 2007]. Using a central population database identifying women with NF1 who are greater than or equal to 20 years old $(\mathrm{N}=304)$, Sharif et al. found that women $<50$ years old with NF1 had a SIR of 4.9 (P < $0.05,95 \%$ CI: 2.4 to 8.8) for the diagnosis of breast cancer. Similarly, Walker et al, showed a SIR of $4.0(\mathrm{P}=0.037,95 \%$ CI: $1.1-10.3)$ for breast cancer in women $<50$ [Walker et al., 2006]. The data from the present study support these findings and are further expanded to assess whether there is an association between race and rates of breast cancer in women with NF1. Importantly, race did not influence the SIR for breast cancer in NF1, suggesting that the risk for breast cancer is independent of race in these patients (Table II).

The increased risk of breast cancer in patients with NF1 reported in this and prior papers [Walker et al., 2006; Sharif et al., 2007] is important to recognize clinically. Evans et al. reported a proportionate mortality ratio of $3.5(\mathrm{P}=0.013,95 \% \mathrm{CI}: 1.3-7.7)$ related to breast cancer in women with NF1, suggesting that there is not only increased risk for developing breast cancer in women with NF1, but also a higher rate of death associated with the breast cancer diagnosis [Evans et al., 2011]. Breast cancer screening guidelines have been established for the general population and for women with known genetic risk factors for breast cancer such as BRCA1 and PTEN syndromes in an effort to decrease mortality from breast cancer through early diagnosis [Saslow et al., 2007; US Preventive Services Task Force, 2009; Mandelblatt et al., 2009]. There are currently no such guidelines for patients with NF1. Based on the estimates by Sharif et al., [2007] women with NF1 <50 years old are considered at moderate risk for developing breast cancer and therefore are recommended to have screening mammography starting at 40 years old in the UK.

In the absence of established guidelines, in our clinic we recommend that women with NF1 $>18$ years have annual clinical breast examination by a trained practitioner. In patients where there are palpable masses on exam, we recommend an initial MRI of the breast to assess for neurofibromas. If no suspected cancerous lesions are seen and benign neurofibromas are confirmed, we follow with annual clinical evaluations unless there is a change on the exam. If there are any suspicious lesions, we will consider additional breast imaging including mammography and possible biopsy.

Women with NF1 who are greater than 40 years old in our clinic are referred for both annual clinical breast examination and mammography. In a woman with NF1 and known prior breast cancer, our recommendation is for annual breast MRI and mammogram. Although these are the practices felt to have the best risk benefit ratio in our clinic, there is a clear need for prospective studies about the optimal diagnostic technique and schedule for breast cancer screening in women with NF1.

The small sample size from a single center limited the power of this study, such that the non-adjusted data approached but did not reach statistical significance. However, when adjusted for the date of diagnosis, the SIR was 4.35 ( $\mathrm{P}=0.0054,95 \% \mathrm{CI}: 1.11$ to 11.83 ) for women under 50 years old. Adjustment for the date of diagnosis can be applied to epidemiologic studies using SEER data and has the benefit of accounting for the medical practice active during the periods of interest [Silverstein et al., 2003]. 
Another potential limitation of this study, given its retrospective nature, is that cases may have been missed due to patients being treated or seen at other institutions. A concerted effort was made to review all sources of data available, including both electronic and paper charts in multiple locations. However, it is not possible to know how many diagnoses were missed due to lack of follow-up in the clinic. Despite this, it would be expected that potential missing data about breast cancer diagnoses would only serve to increase the incidence observed. Therefore, the data from this study represents the minimum incidence of breast cancer among women with NF1 in our patient population.

An important strength of this study is its high proportion of minorities (28\% black women). Adjusting for race did not influence the SIR. This suggests that the recognized higher frequency of breast cancer in younger black women did not influence the results [Aziz et al., 1999; El-Tamer and Wait, 1999].

To further investigate the relationship between NF1 and breast cancer, pooling of patients across multiple centers is necessary. Collaboration between NF1 specialty clinics would be one mechanism to accomplish this goal. However, using patients identified through tertiary and quaternary care centers introduces a bias of ascertainment that could skew results toward cases that are more medically or clinically significant. Whether or not individuals with more severe manifestations of NF1 are more likely to develop breast cancer is unknown. Ideally, a collaborative study would accrue patients from a wider variety of settings in order to minimize ascertainment bias, such as by identifying NF1 patients through a national database or registry. This would allow investigators to identify a large number of individuals from a wide variety of geographic locales who would be eligible for participation to assess the relationship between NF1 and breast cancer in a broad population study.

In conclusion, our data and the collective data from studies in the UK indicate that women with NF1 are at higher risk for breast cancer than the general population, particularly when they are $<50$ years old. Moreover, there is a reported increased risk of breast cancer related death in young women with NF1. In our opinion this justifies early and annual clinical and radiographic screening for breast cancer in these patients. However, research is required to determine the optimal screening method and timing that will allow for earlier diagnosis and hopefully, decreased breast cancer associated morbidity and mortality in women with NF1. Additional research is also required to better understand the relationship between the NF1 mutation and breast cancer pathophysiology.

\section{Acknowledgments}

We would like to extend a warm thanks to the patients and families of the Johns Hopkins Comprehensive Neurofibromatosis Center, without whom this study would not have been possible. Additionally, we would like to thank Gretchen Oswald, MS CGC (Johns Hopkins Comprehensive Marfan Center), for data assistance and advice, Dr. Gareth Evans (University of Manchester) for laying the foundation for this work, and the SEER registry.

This study was supported by the Johns Hopkins Predoctoral Clinical Research Training Program grant number 1TL1RR-025007 from the National Center for Research Resources (NCRR), a component of the National Institutes of Health (NIH).

\section{REFERENCES}

Ardern-Holmes SL, North KN. Therapeutics for childhood neurofibromatosis type 1 and type 2. Curr Treat Options Neurol. 2011; 13:529-543. [PubMed: 21850405]

Aziz H, Hussain F, Sohn C, Mediavillo R, Saitta A, Hussain A, Brandys M, Homel P, Rotman M. Early onset of breast carcinoma in African American women with poor prognostic factors. Am J Clin Oncol. 1999; 22:436-440. [PubMed: 10521053] 
Brems H, Beert E, de Ravel T, Legius E. Mechanisms in the pathogenesis of malignant tumours in neurofibromatosis type 1. Lancet Oncol. 2009; 10:508-515. [PubMed: 19410195]

Brunetti-Pierri N, Doty SB, Hicks J, Phan K, Mendoza-Londono R, Blazo M, Tran A, Carter S, Lewis RA, Plon SE, Phillips WA, O’Brian Smith E, Ellis KJ, Lee B. Generalized metabolic bone disease in neurofibromatosis type I. Mol Genet Metab. 2008; 94:105-111. [PubMed: 18289904]

El-Tamer MB, Wait RB. Age at presentation of African-American and Caucasian breast cancer patients. J Am Coll Surg. 1999; 188:237-240. [PubMed: 10065811]

Evans DG, Baser ME, McGaughran J, Sharif S, Howard E, Moran A. Malignant peripheral nerve sheath tumours in neurofibromatosis 1. J Med Genet. 2002; 39:311-314. [PubMed: 12011145]

Evans DG, Howard E, Giblin C, Clancy T, Spencer H, Huson SM, Lalloo F. Birth incidence and prevalence of tumor-prone syndromes: Estimates from a UK family genetic register service. Am J Med Genet A. 2010; 152A:327-332. [PubMed: 20082463]

Evans DG, O'Hara C, Wilding A, Ingham SL, Howard E, Dawson J, Moran A, Scott-Kitching V, Holt F, Huson SM. Mortality in neurofibromatosis 1: In North West England: An assessment of actuarial survival in a region of the UK since 1989. Eur J Hum Genet. 2011; 19:1187-1191. [PubMed: 21694737]

Huson SM, Harper PS, Compston DA. Von Recklinghausen neurofibromatosis. A clinical and population study in south-east Wales. Brain. Dec; 1988 111(Pt 6):1355-81. (Pt 6). [PubMed: 3145091]

Jondeau G, Michel JB, Boileau C. The translational science of Marfan syndrome. Heart. 2011; 97:1206-1214. [PubMed: 21742617]

Mandelblatt JS, Cronin KA, Bailey S, Berry DA, de Koning HJ, Draisma G, Huang H, Lee SJ, Munsell M, Plevritis SK, Ravdin P, Schechter CB, Sigal B, Stoto MA, Stout NK, van Ravesteyn NT, Venier J, Zelen M, Feuer EJ, Breast Cancer Working Group of the Cancer Intervention and Surveillance Modeling Network. Effects of mammography screening under different screening schedules: Model estimates of potential benefits and harms. Ann Intern Med. 2009; 151:738-747. [PubMed: 19920274]

Montani D, Coulet F, Girerd B, Eyries M, Bergot E, Mal H, Biondi G, Dromer C, Hugues T, Marquette C, O'Connell C, O'Callaghan DS, Savale L, Jais X, Dorfmuller P, Begueret H, Bertoletti L, Sitbon O, Bellanne-Chantelot C, Zalcman G, Simonneau G, Humbert M, Soubrier F. Pulmonary hypertension in patients with neurofibromatosis type I. Medicine (Baltimore). 2011; 90:201-211. [PubMed: 21512413]

National Institutes of Health Consensus Development Conference. Neurofibromatosis. Conference statement. Arch Neurol. 1988; 45:575-578. [PubMed: 3128965]

Riccardi VM. Neurofibromatosis type 1 is a disorder of dysplasia: The importance of distinguishing features, consequences, and complications. Birth Defects Res A Clin Mol Teratol. 2010; 88:9-14. [PubMed: 19691086]

Saslow D, Boetes C, Burke W, Harms S, Leach MO, Lehman CD, Morris E, Pisano E, Schnall M, Sener S, Smith RA, Warner E, Yaffe M, Andrews KS, Russell CA, American Cancer Society Breast Cancer Advisory Group. American Cancer Society guidelines for breast screening with MRI as an adjunct to mammography. CA Cancer J Clin. 2007; 57:75-89. [PubMed: 17392385]

SEER [Internet]. National Cancer Institute; Bethesda, MD: Available from: http://seer.cancer.gov

Sharif S, Moran A, Huson SM, Iddenden R, Shenton A, Howard E, Evans DG. Women with neurofibromatosis 1 are at a moderately increased risk of developing breast cancer and should be considered for early screening. J Med Genet. 2007; 44:481-484. [PubMed: 17369502]

Shirley ED, Sponseller PD. Marfan syndrome. J Am Acad Orthop Surg. 2009; 17:572-581. [PubMed: 19726741]

Silverstein MD, Nietert PJ, Ye X, Lackland DT. Racial disparities in the incidence of lung cancer: The Savannah River region health information system cancer registry, 1991-95. J Health Care Poor Underserved. 2003; 14:23-33. [PubMed: 12613066]

US Preventive Services Task Force. Screening for breast cancer: U.S. Preventive Services Task Force recommendation statement. Ann Intern Med. 2009; 151:716-26. W-236. [PubMed: 19920272] 
Walker L, Thompson D, Easton D, Ponder B, Ponder M, Frayling I, Baralle D. A prospective study of neurofibromatosis type 1 cancer incidence in the UK. Br J Cancer. 2006; 95:233-238. [PubMed: 16786042]

Wilson CH, Griffith CD, Shrimankar J, Douglas F. Gynaecomastia, neurofibromatosis and breast cancer. Breast. 2004; 13:77-79. [PubMed: 14759722] 


\section{Table I}

Demographic characteristics of populations studied.

\begin{tabular}{l|l|l} 
& NF1 & Marfan \\
\hline $\begin{array}{l}\text { Number of female } \\
\text { patients }\end{array}$ & 126 & 47 \\
\hline Minimum age & 20 & 20 \\
\hline Mean age (range) & $36(24-48)$ & $41(27-55)$ \\
\hline Race & & \\
White & $81(64.3 \%)$ & $40(85.1 \%)$ \\
Black & $35(27.8 \%)$ & $4(8.5 \%)$ \\
Asian & $1(0.8 \%)$ & $1(2.1 \%)$ \\
Hispanic & $2(1.6 \%)$ & $0(0 \%)$ \\
Other/Unspecified & $7(5.6 \%)$ & $2(4.3 \%)$ \\
\hline Seen in clinic & $2003-2010$ & $2003-2010$ \\
\hline
\end{tabular}


Table II

SIR of Breast Cancer among Women with NF1 Under Age 50

\begin{tabular}{|c|l|l|}
\hline \multirow{4}{*}{ Unadjusted } & Expected & 1.12 \\
\cline { 2 - 3 } & Actual & 3 \\
\cline { 2 - 3 } & SIR & $2.68(\mathrm{P}=0.076,95 \%$ CI: 0.68-7.29) \\
\hline \multirow{4}{*}{ Adjusted for Race } & Expected & 1.12 \\
\cline { 2 - 3 } & Actual & 3 \\
\cline { 2 - 3 } & SIR & $2.68(\mathrm{P}=0.076,95 \%$ CI: 0.68-7.29) \\
\hline \multirow{4}{*}{$\begin{array}{c}\text { Adjusted for NF1 Prevalence } \\
\text { Adjusted for Date of } \\
\text { Diagnosis }\end{array}$} & Expected & 1.09 \\
\cline { 2 - 3 } & Actual & 3 \\
\cline { 2 - 3 } & SIR & $2.75(\mathrm{P}=0.067,95 \%$ CI: 0.70-7.49) \\
\hline \multirow{4}{*}{$\begin{array}{c}\text { Adjusted for Race, NF1 } \\
\text { Prevalence and Date of } \\
\text { Diagnosis }\end{array}$} & Expected & 0.69 \\
\cline { 2 - 3 } & Actual & 3 \\
\cline { 2 - 3 } & SIR & $4.35(\mathrm{P}=0.0054,95 \%$ CI: $1.11-11.83)$ \\
\cline { 2 - 3 } & Actual & 3 \\
\cline { 2 - 3 } & SIR & $4.41(\mathrm{P}=0.0049,95 \%$ CI: 1.12-12.00) \\
\hline
\end{tabular}


Table III

Characterization of Breast Cancer Cases

\begin{tabular}{|l|l|l|l|}
\hline Patient & Tumor Characteristics & Place of Diagnosis & $\begin{array}{l}\text { Breast Cancer } \\
\text { Diagnosis relative to } \\
\text { intake in the JHCNC }\end{array}$ \\
\hline 1 & Unknown & Outside hospital & Before \\
\hline 2 & $\begin{array}{l}\text { Invasive ductal carcinoma, grade } \\
1\end{array}$ & Outside hospital & Before \\
\hline 3 & Ductal carcinoma in situ, grade 3 & JHH & After \\
\hline 4 & $\begin{array}{l}\text { Ductal carcinoma in situ, with } \\
\text { comedo necrosis }\end{array}$ & JHH & After \\
\hline
\end{tabular}

